Preprints of the

Max Planck Institute for

Research on Collective Goods

Bonn 2010/48

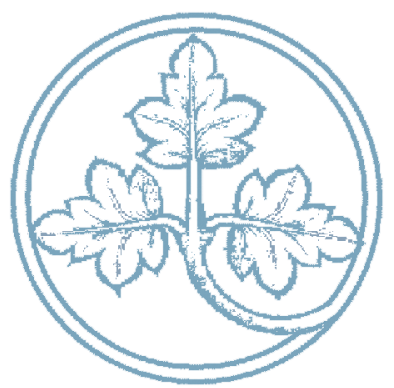

An Experimental Contribution to the Revision of the Guidelines on Research and Development Agreements

Christoph Engel

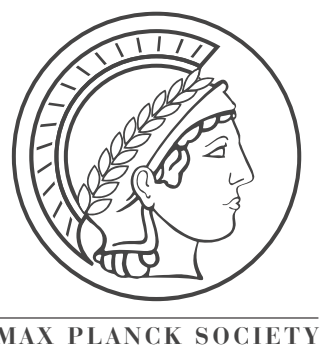




\section{An Experimental Contribution to the Revision of the Guidelines on Research and Development Agreements}

Christoph Engel

December 2010 


\title{
An Experimental Contribution to the Revision of the Guidelines on Research and Development Agreements ${ }^{1}$
}

\author{
Christoph Engel
}

\begin{abstract}
The European Commission is working on a revision of its Guidelines on Research and Development Agreements. On this occasion, this note surveys the existing experimental evidence. Experiments add a number of additional arguments to the normative assessment. R\&D agreements have a much smaller effect on later competition in the product market if they serve as a substitute for incomplete (legal) protection of innovation effort. They may help firms settle the resulting fairness issue, and stay away from investment wars. Using the results from 107 published experiments on oligopoly, a meta-study shows that clearing an R\&D agreement can be beneficial since it removes the additional collusion incentive resulting from fear that, through successful innovation, competitors might gain an advantage. This is the case if the opposite market side has countervailing power, and the more market conditions are stable. By contrast, the meta-data suggests that R\&D agreements increase the risk of collusion in the product market if products are substitutes, if capacity cannot immediately be extended, if market participants may communicate, and if they are experienced; the latter two conditions are very likely to hold in the field.
\end{abstract}

Keywords: antitrust, research and development agreements, block exemption, oligopoly experiments, innovation, meta-study

JEL: D03, D43, K21, L13, L41, O31, O34

1 Helpful comments by Martin Hellwig, Jos Jansen and Alexander Morell are gratefully acknowledged. 


\section{Introduction}

Legal scholars are pleased if the authorities signal that they find their work useful. This may appear so obvious that one wonders why an academic might find it worth the while to mention it. Yet if this scholar spends his time running experiments, practitioners are not among the regular readers of his publications. I therefore was indeed pleased when I recently was invited to present my meta-study on oligopoly experiments ${ }^{2}$ at GD Comp in Brussels. Interaction was lively. The lawyers and economists in the room seemed to like my attempts at using this data for checking back the guidelines on the increased risk of tacit collusion as an argument in merger control ${ }^{3}$. Yet being good policy makers, they asked for an additional, more timely contribution. Currently, the horizontal guidelines ${ }^{4}$ are under review. This review is triggered by the fact that both the block exemption on research and development agreements ${ }^{5}$ and on specialisation agreements ${ }^{6}$ have sunset clauses and expire at the end of 2010. Could my data help the Commission make the right choices they asked before we parted company.

This note is my attempt to oblige. My contribution is a modest one. Actually it is more modest than my unsolicited contributions to a future revision of the merger guidelines. In the merger context, all my contributions concern the risk of the (tacit or explicit) coordination of market behaviour. One should therefore have thought that it would not be more difficult to make a contribution to the application of Art. 101 EC. In the merger context, what experimentalists have tested, i.e. collusion, matters only indirectly. A merger may be blocked since it substantially increases the risk of (tacit) collusion. By contrast, Art. 101 EC directly intervenes into collusive market behaviour. Yet essentially the horizontal guidelines are not about the conditions under which collusion is most likely (which is what the experimenters have been interested in). Rather the guidelines address the tradeoff between potential social benefit from cooperation (e.g. since it makes product or process innovation more likely) and the ensuing cost and risk in terms of reduced competitive pressure. This is of course not to say that exploring this conflict from a behavioural angle would be pointless. Quite the contrary. One might for instance design experiments to test the power of the excuse. Are participants less inclined to regret harm they impose on the opposite market side, and are they less inclined to respect the law, if they may tell themselves: but what I am doing is in society's best interest! One might also want to study the difference between a per se rule and a rule of reason when it comes to compliance. Are experimental participants less prepared to play by the rules if the rule in question is not a bright line rule? Yet this has not been done.

This note confines itself to reporting the existing experimental literature in the practically most important, and comparatively best studied area, research and development cooperation and com-

2 Engel, How Much Collusion? A Meta-Analysis on Oligopoly Experiments, 3 Journal of Competition Law and Economics 491-549 (2007a).

3 OJ 2004 C 31/5, §§ 39-57. The paper doing this is still under review, Engel, Tacit Collusion. The Neglected Experimental Evidence (2007b). http://ssrn.com/abstract=1020889.

OJ 2001 C 3/2.

Regulation EC 2659/2000, OJ L 304/7, Art. 9.

Id. 
petition. Section II surveys the existing experimental literature on research and development cooperation. In Section III, I revert to my meta-study for addressing in more rigorous terms the only question on which I have sufficient data for quantitative argument: does collusion in experimental markets become less pronounced if cost may be reduced, be that through an exogenous shock (think of a change in the price of a raw material) or through the fact that one market participant successfully innovates?

\section{Survey}

The existing block exemption expresses its rationale the following way:

„Cooperation in research and development and in the exploitation of the results generally promotes technical and economic progress by increasing the dissemination of know-how between the parties and avoiding duplication of research and development work, by stimulating new advances through the exchange of complementary knowhow, and by rationalising the manufacture of the products or application of the processes arising out of the research and development". 7

The existing experimental evidence contributes to understanding the motives of market players who decide to do cooperative research. In order to maintain control, experiments stylize facts. In the experiments reported in this note, this is done by introducing a first stage into a market experiment. In this stage, participants may invest. If they do, this yields a deterministic cost reduction. Typically, in the experiment nothing is actually produced; just the cost of actions at the market stage changes. In the experiments the only purpose of cooperation in "innovation" can be a reduction of competitive pressure at the market stage, through harmonizing production cost. This design not only limits the external validity of these experiments. It also deprives experimenters of an interesting behavioural variable. On the one hand, the willingness to later collude might be more limited with true production, since actors hold a mental model of "coopetition": 8 they cooperate in research, and they compete in production and marketing. On the other hand, the fact that they have been in the same boat during the development of the product might make them unwilling to hurt their former cooperation partner when they go on the market.

The experiments directly only speak to the reverse side of the medal. The $R \& D$ agreement should not lead to a "disguised cartel". ${ }^{9}$ Yet in antitrust practice, the risk of tacit collusion is not the only consideration. For the Commission, the key question is this:

"Many horizontal cooperation agreements, however, do not have as their object a restriction of competition. Therefore, an analysis of the effects of the agreement is necessary. For this analysis it is not sufficient that the agreement limits competition between the parties. It must also be likely to affect competition in the market to such an

\footnotetext{
$7 \quad$ Block exemption, Rec. 10; see also Guidelines, 3, 10, 32, 40, 68.

8 Brandenburger/Nalebuff, Co-opetition, New York, 1996.

9 Guidelines, 59; see also Block exemption, Rec. 15.
} 
extent that negative market effects as to prices, output, innovation or the variety or quality of goods and services can be expected““. ${ }^{10}$

It is in the application of these criteria that experimental evidence can be of some help. A single paper addresses the full question. ${ }^{11}$ In the treatment, it gives participants in a duopoly market a chance to agree on the level of cost-reducing investments. Contracts are binding and symmetric. In the baseline, investment decisions must be taken independently. At the market stage, participants compete in price. Explicit collusion is excluded. Participants interact over 35 periods in fixed groups. Every 5 periods, they can invest. There are two conditions. In one condition, the investment only benefits the participants who have made it. In the alternative condition, the other participants can fully appropriate the benefit. This condition is meant to capture the absence of patent protection.

In the experiment, there is much more investment with contracting if the non-investing player can appropriate the result. In this situation, prices in the market are not affected. By contrast, if investment effort is proprietary, prices are significantly and substantially higher if the players have fixed the investment level by contract. This result indicates that the effect on competition in the product market hinges on the way firms construct the R\&D agreement. The more the agreement seems to solve a problem that is not directly related to competitive pressure, the less it is likely to serve as a device for enhancing tacit collusion. This provides tentative backing to the concept of coopetition.

Three more experiments do not give participants a chance to explicitly agree on investment. If there is coordination of investment, it has to be tacit. The experiments measure both investment and later market activity. ${ }^{12}$ The earliest contribution to this literature found no sign of investment coordination. Participants would have maximised their payoffs if they had taken turns in reducing production cost. Then, each of them could have reaped monopoly profits for a number of periods. Yet investment was roughly symmetric. At the market stage, there was least collusion when the effect of investments depended on chance and when the investor had to share the cost advantage with the remaining providers after a limited number of periods. There still was relatively little collusion when the effect of investments was certain, while the investor had to share the advantage with others after a while. Market outcomes most pronouncedly differed from the competitive benchmark if the success of investment was uncertain, the property right was permanent, and when information about investment was private knowledge. Note that the experiment used a double oral auction for determining prices, which is generally known to push prices

10 Guidelines, 19, see also 61.

11 Suetens, Does R\&D Cooperation Facilitate Price Collusion? An Experiment, 66 Journal of Economic Behavior \& Organization 822 - 836 (2008).

12 Jullien/Ruffieux, Innovation, avantages concurrentiels et concurrence. Une analyse expérimentelle des incitations à innover et de l'efficacité des marchés en présence de chocs endogènes, 111 Revue d'Économie Politique 121 - 149 (2001); Darai/Sacco/Schmutzler, Competition and Innovation: An Experimental Investigation, 2009; Sacco/Schmutzler, Is There a U-shaped Relation Between Competition and Investment?, InternaInternational Journal of Industrial Organization (forthcoming); also see Pantz/Ziegelmeyer, Collaborative Networks in Experimental Triopolies, 2004, for a substantially different design of the investment stage. 
very close to the competitive benchmark. ${ }^{13}$ Hence the fact that there is nonetheless quite some collusion indicates that a setting where participants first invest does indeed make later collusion in the market more likely.

Another experiment manipulated the number of suppliers (2 vs. 4) and the strategic variable (price vs. quantity). ${ }^{14}$ While investment was close to the equilibrium prediction when firms competed in quantity, ${ }^{15}$ there was considerable overinvestment when firms competed in price. ${ }^{16}$ The authors discuss competing behavioural explanations, none of which they find fully convincing. A plausible explanation ${ }^{17}$ stems from the profit function. When players competed in price, it was such that the only way to make a positive profit was outperforming the investment of the other player(s). ${ }^{18}$ Since participants dreaded this outcome, they became supercompetitive. ${ }^{19}$ This explanation would be in line with prospect theory. ${ }^{20}$ When individuals perceive an outcome as a loss, compared with their individual reference point, ${ }^{21}$ they become willing to take fairly high risks to prevent the loss from materialising. The authors do not report market outcomes in isolation. Total net profit (after subtracting the investment cost) on average was highly negative when players competed in price. The paper demonstrates two things: at least in the tested setting, tacit collusion at the investment stage was not an issue. R\&D agreements may improve welfare in that they prevent firms from engaging in investment wars. The effect seems to be most relevant if investment laggards expect zero or negative profits.

This explanation finds further support in another experiment from two of the authors of the previous paper. ${ }^{22}$ In this game, two firms interact for 20 announced periods in a market where equilibrium profits are positive. ${ }^{23}$ Both may invest to reduce cost. The authors find substantial underinvestment. Underinvestment is even more pronounced if products are only imperfect substitutes. ${ }^{24}$ Nonetheless, in both cases market behaviour converges toward the equilibrium. This is remarkable. For in this experiment, for the market stage demand is represented by the

13 I can show this using the data from my meta-study (supra note 2), OLS, regressing the proportional deviation from the Walrasian equilibrium on the use of an auction protocol, cons 43.440***, auction $-43.505 * * *, \mathrm{~N}=$ $479, \mathrm{R}^{2}=.115$. Hence the model predicts zero collusion. For the methodology of the meta-study see below III.

14 Darai/Sacco/Schmutzler, Competition and Innovation: An Experimental Investigation, 2009.

15 Technically speaking: in a Cournot market.

16 Technically speaking: in a Bertrand market.

17 Not discussed in the paper.

18 Darai/Sacco/Schmutzler, Competition and Innovation: An Experimental Investigation, 2009, $6 \mathrm{f.}$

19 Technically speaking: they set prices below the Nash equilibrium.

20 Tversky/Kahneman, Advances in Prospect Theory. Cumulative Representation of Uncertainty, 5 Journal of Risk and Uncertainty 297 - 323 (1992).

21 Defining reference points is never easy. In the case at hand, the most likely reference point was zero profit.

22 Sacco/Schmutzler, Is There a U-shaped Relation Between Competition and Investment?, International Journal of Industrial Organization, (forthcoming).

23 Technically speaking: in a Cournot market with differently heterogeneous products.

24 Specifically: when products are perfect substitutes, through learning the investment level converges to the equilibrium over time. This is not expected with imperfect substitutes. 
computer, playing the demand curve. Consequently, demand is passive. In general, this is the environment where collusion is highest. ${ }^{25}$

A further experiment is less relevant for the Guidelines since it only studies investment behaviour (with market outcome and hence payoffs determined by the computer). ${ }^{26}$ The author shows that, in a duopoly with perfect property rights in innovation, investment is very close to the equilibrium, even if participants have a chance to chat. Only if binding contracts are available there is underinvestment, the more so the longer participants interact. By contrast, if the competitor may immediately appropriate the innovation effort, there is less underinvestment than theory predicts. With pure communication ("cheap talk") participants even invest slightly more than the social optimum, while binding contracts are mildly effective. This result suggests that participants see appropriable investment as a fairness issue. They want a chance to appeal to their competitor's sense of fairness before they make themselves vulnerable to exploitation. This points to an additional motive for exempting concerted investment behaviour from Art. 101 EC. This motive is conditional on the quality of the intellectual property rights a firm may unilaterally acquire. A practical illustration would be patent pools, to the extent that they react to the fact that each firm depends on property rights held by its competitors. Even if its own new invention is protected, this gives other firms sufficient threat power to invalidate the temporary monopoly.

A final set of experiments explores R\&D competition, again without testing its effects on product market competition. A first experiment replicates the fact that participants overinvest if they compete in price. ${ }^{27}$ The effect is even stronger in markets of 4 than in markets of 2 . By contrast, when they compete in quantity, there is underinvestment in markets of 4 , and only slight overinvestment in markets of 2 . Overinvestment is also observed in an experiment where one of the players has an initial cost advantage. ${ }^{28}$ These players overinvest heavily to maintain their dominant position. Consequently, in this case asymmetry increases the policy problem, and might provide an additional justification for granting an exemption from Art. 101 EC. Two more experiments explore the social damage resulting from a patent race. ${ }^{29}$ This is more remote in that the winner gains a monopoly, and therefore has no longer a need to coordinate market behaviour. Moreover, since only one firm can have the patent, this induces a pattern of hit and run competi-

25 Again using the data from my meta-analysis (supra note 2), OLS, regressing the proportional deviation from the Walrasian equilibrium on the use of the so called posted offer protocol, cons 1.911, posted offer 46.599 $* * *, \mathrm{~N}=479, \mathrm{R}^{2}=.253$.

26 Suetens, Cooperative and Noncooperative R\&D in Experimental Duopoly Markets, 23 International Journal of Industrial Organization 63 - 82 (2005).

27 Sacco, Competition and Innovation: An Experimental Investigation, 2007.

28 Halbheer/Fehr/Goette/Schmutzler, Self-Reinforcing Market Dominance, 67 Games and Economic Behavior 481 - 502 (2009).

29 Zizzo, Racing with Uncertainty. A Patent Race Experiment, 20 International Journal of Industrial Organization 877 - 902 (2002); Cantner/Güth/Nicklisch/Wieland, Competition in Product Design. An Experiment Exploring Innovation Behavior, 60 Metroeconomica 724 - 752 (2009); also see Crosetto, To Patent or not to Patent. A Pilot Experiment on Incentives to Copyright in a Sequential Innovation Setting, 2010. 
tion. ${ }^{30}$ These papers show that, also from an experimental viewpoint, a patent race may reduce welfare. To prevent this from happening may justify exempting R\&D cooperation from Art. 101 EC.

\section{Meta-Study}

Compared with the standard of the experimental literature, the previous section had to be uncomfortably imprecise. It could only argue qualitatively, although a major advantage of experimental rigour is assessing the absolute and relative magnitude of effects. Of course, the papers reported do so lege artis. But for the purpose of redesigning the horizontal guidelines, one would have to know more about the robustness of the results once the specific parameters of the respective experiment are changed. In principle, this is a job for meta-analysis. Yet the reported papers are too diverse, and their number is too small, to make meta-analysis meaningful. In conclusion of this note, I therefore revert to my meta-study of all oligopoly experiments until 2006. Actually, the period of observation is not a limitation. For the papers that are covered by the previous section, but not by the meta-analysis, unfortunately do not report data on the market stage in such a way that I could add these data-points to the meta-analysis. ${ }^{31}$

The contribution I can make has, however, limited scope. I can only make statements regarding the repercussions on the product market. The independent variable of interest is the possibility for asymmetric shocks regarding production cost. ${ }^{32}$ Asymmetric means that potentially only some suppliers benefit from the cost reduction. In my dataset, these shocks may, but need not, result from purposeful innovation. I have also added two experiments where single firms can benefit from exogenous cost reductions, ${ }^{33}$ and another where two previously independent firms can reduce cost after their merger, through synergies. ${ }^{34}$

I have two dependent variables: the proportional deviation of the market outcome, regarding the strategic variable (price or quantity), from the outcome if competition is perfect; and the proportional deviation from the equilibrium. ${ }^{35}$ Both indices are normalised on the interval $[0,100] .0$ means no collusion at all. 100 means the outcome that maximises joint profit of suppliers. From

30 This is the main topic of Zizzo, Racing with Uncertainty. A Patent Race Experiment, 20 International Journal of Industrial Organization 877 - 902 (2002).

31 Most papers do not have a market stage in the first place. Darai/Sacco/Schmutzler, Competition and Innovation: An Experimental Investigation, 2009; Sacco/Schmutzler, Is There a U-shaped Relation Between Competition and Investment?, International Journal of Industrial Organization, (forthcoming) do. But for the market stage, they only have line graphs, from which mean market behaviour cannot be reconstructed with sufficient precision. Suetens, Does R\&D Cooperation Facilitate Price Collusion? An Experiment, 66 Journal of Economic Behavior \& Organization 822 - 836 (2008) had already been covered as a working paper.

32 The variable is dummy coded. If it has expression 0, production cost stays constant for all suppliers. If it has expression 1, production cost may change for some or all suppliers during the experiment.

33 Davis/Wilson, Firm-Specific Cost Savings and Market Power, 16 Economic Theory 545 - 565 (2000); Isaac/Reynolds, Two or Four Firms. Does It Matter?, 9 Experiments Investigating Market Power 95 - 119 (2002).

34 Davis/Wilson, Horizontal Merger, Strategic Buyers and Fixed Cost Synergies. An Experimental Investigation, 2003.

35 For the construction of the indices see Engel, How Much Collusion? A Meta-Analysis on Oligopoly Experiments, 3 Journal of Competition Law and Economics 491 - 549 (2007a). 
a normative perspective, the former index is of greater interest. For it is directly related to the welfare loss. The latter index informs the Commission to which degree it may expect a problem (or a solution) if it intervenes, or if it abstains from intervention.

Although this is only partial evidence, it may help the Commission revise the list of criteria it has laid down for assessing R\&D agreements:

"The nature of an agreement relates to factors such as the area and objective of the cooperation, the competitive relationship between the parties and the extent to which they combine their activities. These factors indicate the likelihood of the parties coordinating their behaviour in the market“ “ ${ }^{36}$

"Depending on the market position of the parties and the concentration in the market, other factors such as the stability of market shares over time, entry barriers and the likelihood of market entry, the countervailing power of buyers/suppliers or the nature of the products (e.g. homogeneity, maturity) have to be considered as well““. ${ }^{37}$

Statistically speaking, to this end, the main effect of "innovation", i.e. the possibility of a cost reduction for some suppliers, is only of limited interest. The interaction effect is more important: Does the respective feature of the market have a different effect when there is also room for asymmetric cost shocks? To explain the methodology, take model 2 in table 1 . In this model, the main effect of innovation is positive, indicating that, everything else held constant, collusion increases by $28 \%$ if participants may invest into cost reductions. Yet through the interaction effect, the risk of tacit collusion decreases by $52 \%$ if the innovation option is introduced into a market where products are substitutes. The net effect is $28 \%-52 \%=-24 \%$. Hence while the innovation option increases the risk of collusion when products are homogeneous, it decreases collusion if products are heterogeneous.

If the interaction effect is positive, clearing an R\&D agreement might pay a double dividend, since it also reduces the threat that competitors gain an advantage through reducing their cost. If the agreement removes this threat, it also removes the additional motive for collusion. Yet whether this holds also depends on the sign and the size of the main effect. Consequently, if the interaction effect is positive, ultimately the measure of interest is the net effect, i.e. the main + the interaction effect. If the interaction effect is negative, clearing the agreement would remove this normatively desirable effect. This holds irrespective of the sign and the size of the main effect. Of course, if the net effect remains positive, there is still a normative problem. But it at least is smaller if the R\&D agreement is not allowed to become effective.

Since space is restricted, I only report significant interaction effects. ${ }^{38}$ If I take deviations from the efficient price or quantity to be the norm, I do indeed find a number of negative interaction effects, indicating that allowing the agreement to go through would increase the risk of collusion since it removes the threat of a cost advantage for the competitor. This holds if products are sub-

36 Guidelines, 21.

37 Guidelines, 30.

38 Since otherwise marginal effects could no longer be directly read off the coefficients (and to preempt problems of multicollinearity), I work with centered variables. 
stitutes, if market participants can communicate, and if they are experienced. In model 3 I also find a negative interaction effect if one firm is a (Stackelberg) leader, and the larger the number of suppliers in the market. ${ }^{39}$ Yet these effects swap sign if I control for the remaining explanatory variables in model $9 .^{40}$ By contrast, in the complete model I also find a negative interaction effect if the strategic variable is quantity. ${ }^{41}$ In the field, this is a plausible assumption when capacity cannot easily be extended in the short run. ${ }^{42}$

Whenever the interaction effect is positive, I also find a positive net effect. Hence I only have cases where clearing the $R \& D$ agreement promises a double dividend. This is true if the opposite market side is active, ${ }^{43}$ and the more market conditions are stable. ${ }^{44}$ In the complete model, I also find positive net effects for sequential interaction, and for an increase in the number of competitors.

As the considerably smaller $\mathrm{R}^{2}$ shows, the available independent variables generally explain deviations from the competitive equilibrium ${ }^{45}$ less well. ${ }^{46}$ For two variables that matter for explaining the degree of inefficiency I do not find a significant interaction effect: the number of competitors, and stability. The interaction term between innovation and the product being a substitute is significant only in the complex models 4 and 9. By contrast, for the interaction with a first mover advantage and with competition in quantity, simpler models suffice than with the alternative dependent variable.

If the Commission is concerned about deviations from the equilibrium, clearing an $R \& D$ agreement is problematic if firms compete in quantity. This was also true with the alternative dependent variable, indicating that this is a robust situation where the risk of a competitor reducing cost fosters competition. Yet for all other independent variables, the interaction effect with innovation and net effects have opposite sign, compared with the regressions explaining deviations from the efficient market outcome. The fact that the opposite market side is active now implies stiffer competition when cost may be unilaterally reduced. Surprisingly, the same also holds if suppliers may post prices. ${ }^{47}$ This implies that customers may only refuse to deal, but have no chance to negotiate, as customarily in a department store. Since this protocol makes buyers relatively inac-

39 In the experiment: if suppliers interact sequentially, such that one moves before the other.

40 In this model, some of the interaction effects are missing since they are perfectly collinear with other explanatory variables.

41 Technically: in Cournot markets.

42 For the underlying theory see Kreps/Scheinkman, Quantity Precommitment and Bertrand Competition Yields Cournot Outcomes, 14 Bell Journal of Economics 326 - 337 (1983).

43 The experimental proxy is the fact that demand is not executed by the computer but represented by human subjects.

44 The experimental proxy is the number of rounds suppliers interact. In model 8, the net effect remains positive if I add the three way interaction with products being substitutes.

45 Technically speaking: the Nash equilibrium.

46 The smaller number of observations results from the fact that the Nash equilibrium cannot always be calculated since some papers have not reported sufficient detail.

47 The interaction with this variable is insignificant with the alternative dependent variable, which is why it does not show up in table 2 . 
tive, one might have expected a positive coefficient. ${ }^{48}$ By contrast, the fact that products are substitutes, that one firm is a Stackelberg leader, and that firms may communicate implies larger deviations from the equilibrium if competitor's cost may fall. Since in all these cases, also the net effect is positive, clearing an $R \& D$ agreement promises a double dividend (if considered from the angle of the equilibrium). Interestingly, the net effect is also positive if experimenters have given suppliers a chance to conclude binding agreements. This can be read as direct experimental evidence in favour of granting the block exemption.

\section{Conclusion}

A well designed experiment may prove causality. With field data, this is much more difficult. Yet the major methodological advantage of experiments is also the source of the biggest limitation. In the interest of isolating causes, experiments severely stylize facts. From a policy perspective, experiments therefore hardly ever settle the case. Yet they are a useful supplement to theory, field evidence, comparative law, and case law. This note shows to which degree this statement also holds for the regulation of R\&D agreements.

48 The result is also not an artefact of the fact that I separately explain the deviation from the Nash equilibrium by buyers being human, and by the posted offer institution. While the interaction effect with the latter drops out in the complete model (model 9) due to collinearity, it survives in a model with only these two explanatory variables, innovation, and all interaction terms. Both interaction terms of interest are significant, and both are negative. Even the interaction term between human buyers and the posted offer institution is negative (albeit insignificant). 


\begin{tabular}{|c|c|c|c|c|c|c|c|c|c|}
\hline & model 1 & model 2 & model 3 & model 4 & model 5 & model 6 & model 7 & model 8 & model 9 \\
\hline innovation & $27.833^{*}$ & $27.291^{*}$ & $18.107 * * *$ & $26.240^{*}$ & $28.683^{*}$ & 21.607 & -13.153 & $35.595^{*}$ & 6.386 \\
\hline substitute & & $37.551^{* * *}$ & $40.558 * * *$ & & & & & $39.310 * * *$ & $34.265 * * *$ \\
\hline innXsubst & & $-52.046 * * *$ & $-37.969 * * *$ & & & & & & \\
\hline \multicolumn{2}{|l|}{ inn+innXsubst } & -24.755 & -19.862 & & & & & & \\
\hline sequential & & & 3.578 & & & & & & 4.236 \\
\hline innXseq & & & $-21.390 *$ & & & & & & 22.889* \\
\hline inn+innXseq & & & -3.283 & & & & & & 27.125 \\
\hline \multicolumn{2}{|c|}{ strategic_variable } & & $-21.875^{* * *}$ & & & & & & $-16.228^{* * *}$ \\
\hline innXstrat & & & -20.33 & & & & & & $-68.182 * * *$ \\
\hline inn+innXstrat & & & & & & & & & -84.41 \\
\hline substXseq & & & 10.388 & & & & & & \\
\hline substXstrat & & & $27.230 * * *$ & & & & & & \\
\hline seqXstrat & & & $-15.724 * *$ & & & & & & \\
\hline \multicolumn{2}{|l|}{ human_buyer } & & & $-34.135 * * *$ & & & & & $-17.328^{* * *}$ \\
\hline innXhum & & & & $28.551^{*}$ & & & & & $34.065 * * *$ \\
\hline inn+innXhum & & & & 54.791 & & & & & 16.737 \\
\hline agreement & & & & & $22.495^{* *}$ & & & & -13.225 \\
\hline innXagr & & & & & $138.042 * *$ & & & & \\
\hline inn+innXagr & & & & & 166.725 & & & & \\
\hline \multicolumn{2}{|l|}{ communication } & & & & -11.234 & & & & 18.548* \\
\hline innXcomm & & & & & $-42.908 * *$ & & & & \\
\hline \multicolumn{2}{|l|}{ inn+innXcomm } & & & & -14.225 & & & & \\
\hline experience & & & & & & $-10.739 * *$ & & & -4.726 \\
\hline innXexp & & & & & & $-38.841 * *$ & & & \\
\hline inn+innXexp & & & & & & -17.234 & & & \\
\hline marketsize & & & & & & & $-5.787 * * *$ & & $3.712 * * *$ \\
\hline innXma & & & & & & & $-32.705^{*}$ & & $13.080 * * *$ \\
\hline inn+innXma & & & & & & & -45.858 & & 16.792 \\
\hline rounds & & & & & & & & $-0.357 * * *$ & $-0.277 * * *$ \\
\hline innXrounds & & & & & & & & $0.962 * *$ & -0.291 \\
\hline \multicolumn{2}{|c|}{ inn+innXrounds } & & & & & & & 0.605 & -0.291 \\
\hline \multicolumn{2}{|c|}{ substXrounds } & & & & & & & 0.117 & -0.333 \\
\hline \multicolumn{2}{|c|}{ innXsubstXrounds } & & & & & & & $4.378 * * *$ & $3.139 * * *$ \\
\hline net3 & & & & & & & & 40.935 & 2.571 \\
\hline Constant & $34.936 * * *$ & $36.578^{* * *}$ & $35.453^{* * *}$ & $36.950 * * *$ & $36.382 * * *$ & $35.974 * * *$ & $57.016 * * *$ & $28.053 * * *$ & $36.358 * * *$ \\
\hline Observations & 479 & 479 & 465 & 479 & 479 & \begin{tabular}{l|l}
479 \\
\end{tabular} & 479 & 479 & 465 \\
\hline R-squared & 0.024 & 0.157 & 0.286 & 0.135 & 0.059 & 0.033 & 0.134 & 0.186 & 0.392 \\
\hline \multicolumn{3}{|c|}{$* * * \mathrm{p}<0.01, * * \mathrm{p}<0.05, * \mathrm{p}<0.1$} & & & & & & & \\
\hline
\end{tabular}

Table 1: Proportional Deviation from the Market Clearing Price or Quantity

variables: innovation (0 1): participants may invest into cost reductions substitute (0 1): products are heterogeneous

sequential (0 1): (at least) one participant knows other participants' choices before she moves strategic variable (0 1): 0 = price, 1 = quantity

human buyer (0 1): opposite market side is represented by experimental subjects

agreement ( 0 1): participants have the option to explicitly coordinate market behaviour

communication $(01)$ : at least one participant may send a message to the other participants before they move

experience (0 1): participants have played similar games before

marketsize (2 25): number of experimental suppliers

rounds (1 100): number of repetitions

$\mathrm{X}$ indicates interaction effects

inn + an interaction effect indicates net effects 


\begin{tabular}{|c|c|c|c|c|c|c|c|c|c|}
\hline & model 1 & model 2 & model 3 & model 4 & model 5 & model 6 & model 7 & model 8 & model 9 \\
\hline innovation & -2.989 & -20.082 & -13.178 & -26.302 & 2.508 & $-52.317 * * *$ & -3.7 & -8.486 & $-59.841 * * *$ \\
\hline substitute & & & & -2.163 & & & 0.693 & 1.975 & -12.557 \\
\hline innXsubst & & & & $122.374 *$ & & & 35.948 & 45.521 & $91.680 *$ \\
\hline \multicolumn{2}{|l|}{ inn+innXsubst } & & & 96.072 & & & & & 31.839 \\
\hline sequential & & -16.321 & & $-20.080 *$ & & & & & -13.723 \\
\hline innXseq & & $86.205^{* *}$ & & $139.508^{*}$ & & & & & $161.008^{* * *}$ \\
\hline inn+innXseq & & 66.123 & & 113.206 & & & & & 101.167 \\
\hline substXseq & & & & $-149.639 * * *$ & & & & & \\
\hline \multicolumn{2}{|c|}{ strategic_variable } & & 0.409 & -1.85 & & & & & 11.866 \\
\hline innXstrat & & & $-110.017 * *$ & $-187.068 * *$ & & & & & $-139.161^{* *}$ \\
\hline inn+innXstrat & & & -123.195 & -213.37 & & & & & -199.002 \\
\hline substXstrat & & & & -13.178 & & & & & \\
\hline seqXstrat & & & & $-30.516 * *$ & & & & & \\
\hline posted & & & & & $28.728^{*}$ & & & & $61.544 * * *$ \\
\hline innXposted & & & & & $-59.625^{*}$ & & & & \\
\hline \multicolumn{2}{|l|}{ inn+innXposted } & & & & -57.117 & & & & \\
\hline \multicolumn{2}{|l|}{ human_buyer } & & & & & $-21.806 * * *$ & & & 4.565 \\
\hline innXhum & & & & & & $-387.102^{* * *}$ & & & $-341.790 * * *$ \\
\hline inn+innXhum & & & & & & -439.419 & & & -401.631 \\
\hline agreement & & & & & & & $27.525 * * *$ & & 49.336* \\
\hline innXagr & & & & & & & $55.483^{*}$ & & \\
\hline inn+innXagr & & & & & & & 51.783 & & \\
\hline substXagr & & & & & & & $30.276 * *$ & & \\
\hline \multicolumn{2}{|l|}{ communication } & & & & & & & $23.608^{* * *}$ & -5.553 \\
\hline innXcomm & & & & & & & & $69.634^{*}$ & \\
\hline \multicolumn{2}{|l|}{ inn+innXcomm } & & & & & & & 61.148 & \\
\hline substXcomm & & & & & & & & $34.704 * * *$ & \\
\hline Constant & -2.053 & -2.965 & -1.607 & -3.597 & -4.131 & -4.802 & -2.657 & -2.846 & -6.262 \\
\hline Observations & 404 & 404 & 392 & 392 & 404 & 404 & 404 & 404 & 392 \\
\hline R-squared & 0 & 0.017 & 0.015 & 0.094 & 0.024 & 0.06 & 0.015 & 0.02 & 0.141 \\
\hline
\end{tabular}

Table 2: Proportional Deviation from the Equilibrium Price or Quantity 